ХИМИЧЕСКАЯ ТЕХНОЛОГИЯ

УДК 625

DOI: 10.34708/GSTOU.2019.18.4.007

\title{
ВКЛАД ГРОЗНИИ В РАЗВИТИЕ ПРОЦЕССА АЛКИЛИРОВАНИЯ В СССР В 1960-е ГОДЫ
}

\author{
(c) X.X. Ахмадова, М.X. Магомадова, Й.А. Тасуева \\ ГГНТУ им. акаА. М.А. Миммионщикова, Грозный, Россия
}

\begin{abstract}
Целью работы является установление вклада ГрозНИИ в развитие процесса алкилирования в СССР в 1960-е годы.

Авторами установлено, что все исследования и реконструкции, касающиеся процесса сернокислотного алкилирования на отечественных НПЗ в 1960-е годы и вплоть до 1990-х годов, проводились при участии и под руководством ГрозНИИ.

Для усовершенствования технологии процесса алкилирования и обмена опытом ГрозНИИ осуществляло сбор и обобщение основных данных, характеризующих работу установок Орского, Куйбышевского, Ново-Куйбышевского, Ново-Уфимского, Ново-Бакинского, Красноводского и Новогрозненского НПЗ за период 1960-е годы.

В результате обследований и обобщения опыта эксплуатации алкилирующих установок ГрозНИИ совместно с рядом заводов были сделаны и частично внедрены рекомендации по улучшению показателей их работы, в частности по оптимизации температурного режима в реакторе, по увеличению концентрации циркулирующего изобутана в системе, по изменению схемы подачи изобутана с параллельной на последовательную для улучшения условий осуществления реакции алкилирования, по подготовке сырья и увеличению ресурсов сырьевого парка, по замене паровых турбин на электродвигатели и т.д.

В 1968 году головные функции по процессу производства алкилбензина в СССР были поручены ГрозНИИ, как научно-исследовательскому институту, внесшему значительный вклад в развитие и становление отечественного процесса алкилирования.
\end{abstract}

Ключевые слова: сернокислотное алкилирование, ГрозНИИ, алкилбензин, объемы производства, установки, контакторы, реконструкция, сырье.

За период с начала промышленной эксплуатации первой алкилирующей установки №25 в Грозном в 1943 г. и в течение 1960-х годов ГрозНИИ была проделана значительная работа по улучшению показателей действующих отечественных установок алкилирования: проведены обследования практически всех установок сернокислотного алкилирования в нефтеперерабатывающей отрасли Союза с обобщением опыта их эксплуатации и проведением технико-экономического анализа их работы.
В результате обследований и обобщения опыта эксплуатации установок ГрозНИИ совместно с рядом заводов были сделаны и частично внедрены рекомендации по улучшению показателей их работы, в частности по оптимизации температурного режима в реакторе, по увеличению концентрации циркулирующего изобутана в системе, по изменению схемы подачи изобутана с параллельной на последовательную для улучшения условий осуществления реакции алкилирования, по подготовке сырья и увеличению сырьевого 
парка, по замене паровых турбин на электродвигатели и т.д.

Также ГрозНИИ были пересмотрены и утверждены в Министерстве НП и НХ промышленности СССР новые технологические регламенты работы всех алкилирующих установок отечественных НПЗ отрасли, в которых предусматривалось улучшение технологической схемы и режима работы установок (изменение схемы подачи в реактор изобутана и олефинов, увеличение числа оборотов вала мешалки, упорядочение операций по перегрузке кислоты и др.).

В 1968 году головные функции по процессу производства алкилбензина в СССР были поручены ГрозНИИ, как научно-исследовательскому институту, внесшему значительный вклад в развитие и становление отечественного процесса алкилирования.

В 1968 году в СССР было выработано 484 тыс. тонн алкилата, израсходовано 960 тыс. тонн сырья и 116 тыс. тонн серной кислоты [7]. В 1969 г. выработка алкилата в стране составила 0,495млн. т.

Средний удельный расход серной кислоты по отрасли составлял 241 кг на тонну алкилата. Качество алкилата было низким - октановое число в чистом виде моторным методом составляло 88,0 пункта.

За период 1943-1970-е годы в СССР по научно-исследовательским данным ГрозНИИ было построено 12 установок сернокислотного алкилирования и 4 установки были получены по программе ленд-лиза из США. Из 16 действующих в 1970 г. алкилирующих установок в Союзе эксплуатировались: свыше 20 лет две установки, 14-20 лет - 12 установок, 6 лет - одна установка и 2 года одна установка (25/7 в г. Ярославле) $[1,2]$.

В 1940-е годы были построены 2 алкилирующие установки: в 1943 г. - первая грозненская № 25 и в 1946 г. - первая импортная установка 25-5 на Орском НПЗ, полученная по ленд-лизу. По этой программе также были получены установки алкилирования: в 1951 г. установка 24-46 на Красноводском НПЗ, в 1952 г. установка 24-36 на Куйбышевском НПЗ, в 1953 г. установка 23-16 на Гурьевском НПЗ.
В 1953 г. были построены установки №251 на Ново-Грозненском НПЗ и две установки 51-52 на Ново-Бакинском НПЗ. В 1954 г. была построена вторая алкилирующая установка №25-2 в Грозном.

В 1954-1955 г. был построен первый в СССР блок алкилирования, состоящий из двух установок 25-4-1 и 25-4-2 на Ново-Уфимском НПЗ.

В 1955 г. также были построены установки сернокислотного алкилирования на Салаватском и Омском НПЗ. В 1956 г. была введена в число действующих установка сернокислотного алкилирования 25-4 на Ново-Куйбышевском НПЗ. Всего в 1950-е годы было построено 12 установок сернокислотного алкилирования.

В 1960-е годы были введены в эксплуатацию всего две установки алкилирования: в 1964 г. одна установка №25-6р сернокислотного алкилирования на Сызранском НПЗ и в октябре 1968 г. вторая на Ново-Ярославском НПЗ [9].

Проект алкилирующей установки Ново-Ярославского НПЗ под шифром №25/7, был выполнен ВНИПИнефтью на основании научно-исследовательских данных ГрозНИИ. Эта установка в СССР, оснащенная самым современным оборудованием, в частности каскадным контактором с реакционной и отстойной секциями, была на тот период по используемой технологии самой передовой в отечественной отрасли [10].

Реакционная секция имела пять каскадов, в каждом из которых были расположены мешалки, обеспечивающие интенсивный контакт кислоты с реагирующими углеводородами. Циркулирующий изобутан и серная кислота подавались в первый каскад и последовательно перетекали из каскада в каскад.

Bсе изменения и реконструкции, касающиеся процесса сернокислотного алкилирования на отечественных НПЗ в 1960-е годы и вплоть до 1990-х годов, проводились при участии и под руководством ГрозНИИ.

Для усовершенствования технологии процесса алкилирования и обмена опытом ГрозНИИ осуществляло сбор и обобщение основных данных, характеризующих работу установок Орского, Куйбышевского, Ново-Куйбы- 
шевского, Ново-Уфимского, Ново-Бакинского, Красноводского и Ново-Грозненского НПЗ за период 1960-е годы [2].

Процесс на этих установках осуществлялся практически по одинаковой схеме, согласно которой все олефиновое сырье и изобутановый рисайкл подвергались смешению в емкости. Полученная смесь затем параллельными потоками подавалась в каждый из контакторов установки, куда вводилась 98\%-ная серная кислота, при понижении концентрации которой до $84-85 \%$ циркуляция ее в системе прекращалась, и кислота выгружалась из контакторов.

В результате анализа работы алкилирующих установок СССР, проведенного ГрозНИИ за период 1960-е годы, были установлены недостатки технологии процесса, конструкции реакторов, выявлены проблемы с сырьем и его качеством.

Bo-nepвыx, было установлено, что все перечисленные алкилирующие установки, за исключением установки Орского НПЗ, работали не по проектной схеме: были выключены одна ступень защелачивания, водная промывка сырья, сырьевые аммиачные холодильники и узлы для регенерации щелочи.

Так, на алкилирующих установках НГНПЗ была выключена пропановая колонна, на Красноводском НПЗ аммиачный хладагент был заменен на пропановый и т.д.

Bo-6mopbx, конструкции реакторов алкилирующих установок были несовершенными. Все алкилирующие установки, кроме установки №25/7НЯНП3, были оснащены вертикальными реакторами с внешним охлаждением устаревшей конструкции, производительность установок была невысокой - 30-45 т.т/год по алкилату, большинство контакторов было морально и физически устаревшим.

Так, большей частью использовались контакторы старой конструкции с аммиачным охлаждением вместо углеводородного, а число этих контакторов было явно недостаточное для создания высокой концентрации изобутана в зоне реакции.

Число контакторов на алкилирующих установках отечественных НПЗ было также различным:
- на Ново-Грозненском, Куйбышевском и Ново-Куйбышевском НПЗ работало по 3 контактора, из них 2 - рабочих, 1 - резервный.

- на Орском, Ново-Бакинском, Ново-Уфимском НПЗ работало по 3 рабочих контактора без наличия резервных.

На Красноводском НПЗ было установлено 3 рабочих контактора и 2 резервных.

Отрицательную роль при осуществлении процесса алкилирования играло несоответствие числа оборотов вращения мешалок турбины контакторов проектным данным.

На большинстве алкилирующих установок отечественных НПЗ обороты вращения мешалок турбин не превышали 2000 вместо 3000 об/мин, предусмотренных проектом: на Красноводском, Ново-Уфимском и Ново-Куйбышевском НПЗ обороты мешалок были снижены до 1350-1500 об/мин. Наибольшее число вращения мешалок турбин контакторов было достигнуто на Орском НПЗ - до 2500 об/мин.

B-mpeтьих, работа ряда алкилирующих установок Союза в 1960-е годы в основном осуществлялась в условиях недостатка количества сырья и его низкого качества, несоответствующего нормальному проведению процесса алкилирования. Соответственно, из-за недостатка сырья имеющиеся мощности установок алкилирования были загружены на 70-80\%.

Так, на НГНПЗ установки №25-1 и №25-2 загружались поочередно: одна из них работала на мощности, превышающей проектную на 20$25 \%$, вторая простаивала или перерабатывала остаток сырья, работая периодически на полной мощности.

На Ново-Уфимском НПЗ две установки №25-4-1 и №25-4-2 работали поочередно.

На ряде заводов отрасли для ликвидации дефицита сырья вовлекали в сырье алкилирующих установок фракции $\mathrm{C}_{3}$ и $\mathrm{C}_{5}$. Например, на Ново-Бакинском, Куйбышевском и Орском НПЗ использовали сырье с добавками до 10\% фракций $\mathrm{C}_{3}$ и до $20-25 \%$ фракции $\mathrm{C}_{5}$. В результате увеличивался выход легкого алкилата до $60 \%$ от сырья [2].

Однако значительное количество пропилена, амиленов и гексиленов, содержащихся в сырье Ново-Бакинского и Куйбышевского НПЗ, приводило к повышению расхода серной 
кислоты до 220-250 кг/т алкилата, на Орском НПЗ расход серной кислоты был несколько ниже и составлял 150 кг/т алкилата.

Отрицательным с точки зрения расхода серной кислоты являлось также отсутствие возможности на многих заводах готовить сырье постоянного состава путем предварительного смешения его компонентов перед подачей в контакторы. ГрозНИИ было установлено, что подача сырья непосредственно с установок термического и каталитического крекинга приводила в ряде случаев к значительному понижению соотношения изобутан : олефины и повышению расхода серной кислоты.

$\boldsymbol{B}$-четвертых, на большинстве отечественных алкилирующих установок технологический режим, заданный по проекту, также в основном не выдерживался. На ряде алкилирующих установок отечественных НПЗ температура в контакторах повышалась до $12-14^{\circ} \mathrm{C}$, а на Красноводском НПЗ повышалась до $15-18^{\circ} \mathrm{C}$.

Для улучшения работы отечественных установок алкилирования ГрозНИИ в 1960-е годы на некоторых НПЗ был проведен ряд реконструкций.

Весьма положительными являлись усовершенствования, внесенные в схему работы алкилирующих установок на ряде заводов по совместной инициативе инженерно-технических работников ГрозНИИ и НПЗ. Сюда в первую очередь относятся: изменение схемы подачи олефинов и изобутана в контакторы, осуществленное на Ново-Грозненских НПЗ; депропанизация продуктов реакции на Куйбышевском НПЗ; изменение аммиачного охлаждения на пропановое на Красноводском НПЗ и др.

Так, например, начиная с 1960 г. для снижения расхода серной кислоты и увеличения выхода алкилата была изменена схема подачи сырья с параллельной на последовательную сначала на установке №25-2 НГНПЗ, затем в 1963 г. на установке №25-1.

Такую переобвязку контакторов на отечественных алкилирующих установках, аналогично проведенной на Ново-Грозненском НПЗ, по рекомендациям ГрозНИИ намечалось в ближайшей перспективе провести на всех заводах.

Применение изменений в схеме грозненской алкилирующей позволило значительно повысить соотношение изобутан : олефины в зоне реакции. В Грозном, где значительно был развит процесс термического крекинга и соотношение изобутан : олефины не превышало $1,05-1,1: 1$, а при изменении схемы в зоне реакции - это соотношение повышалось: при наличии трех контакторов до - 8:1, при наличии двух контакторов - до 5,5-6:1.

На остальных отечественных алкилирующих установках это соотношение не превышало 5:1-7:1 вследствие работы по параллельной схеме обвязки контакторов.

Повышение этого соотношения при осуществлении работы контакторов по последовательной схеме способствовало снижению расхода серной кислоты в процессе.

При использовании трех контакторов расход серной кислоты составлял 130, а при двух - 145-160 кг/т алкилата.

Время пребывания при последовательном питании также уменьшалось и составило в первом контакторе 12, во-втором - 11 и в третьем - 10 мин вместо 18 мин при параллельном их включении.

В 1963 г. на второй Грозненской алкилирующей установке №25-1 в период освоения новой схемы при несколько ухудшенном качестве сырья расходные показатели установки значительно улучшились. Так, расход серной кислоты составил 180 кг/т алкилата вместо 220-250 кг/т по старой схеме.

На алкилирующих установках отрасли по рекомендациям ГрозНИИ была проведена реконструкция с заменой устаревших вертикальных контакторов с аммиачным охлаждением на современные горизонтальные контакторы с охлаждением за счет испарения части продуктов реакции с увеличением числа контакторов до трех, также проводились исследования по разработке новых конструкций контакторов с усовершенствованной системой охлаждения, позволяющих повысить выход и качество алкилата.

Для совершенствования работы алкилирующих установок НПЗ Союза ГрозНИИ было предложено [3,2]:

- строго придерживаться оптимального режима контакторного и ректификационного блока установок, предусмотренных проектом, 
особенно в части температуры реакции и числа оборотов турбины;

- осуществлять предварительную подготовку сырья путем смешения ББФ термического и каталитического крекинга;

- осуществить переобвязку контакторов с параллельной схемы на последовательную с увеличением числа контакторов не меньше трех;

- ввести в эксплуатацию пропановую колонну для депропанизации изобутанового рисайкла;

- загрузку алкилирующих установок путем вовлечения ресурсов фракций $\mathrm{C}_{3}$ и $\mathrm{C}_{5}$ считать нежелательной без существенной реконструкции установок.

Кроме того, в 1960-е годы на заводах отрасли ГрозНИИ прорабатывались вопросы об осуществлении отдельных рекомендаций, направленных на снижение расходных показателей алкилирующих установок, в частности:

1. По подготовке сырья:

- осуществление смешения сырья термического и каталитического крекинга в специальных емкостях с целью подачи его в зону реакции однородного углеводородного состава;

- удаление влаги с помощью химических, физических или других методов;

- вовлечение в переработку бутан-бутиленовой фракции с минимальным содержанием примесей $\mathrm{C}_{3}$ и $\mathrm{C}_{5}$;

- более полная очистка сырья от сернистых соединений путем включения в схему второй ступени очистки, особенно при переработке сернистого сырья.

2. Осуществление тщательной зачистки контакторов от отработанной кислоты.

3. Осуществление работы блока ректификации по полной схеме.

4. Получение изобутанового рисайкла, чистотой не ниже $90 \%$.

5. Понижение температуры в контакторах до $8^{\circ} \mathrm{C}$ и повышение числа оборотов турбины до 3000 в минуту.

Осуществление приведенных рекомендаций позволяло значительно улучшить расходные показатели на отечественных алкилирующих установках.

Для решения вышеуказанных вопросов в ГрозНИИ проводилось значительное количе- ство исследований по процессу алкилирования и изучались возможные пути реконструкции алкилирующих установок $[4,5]$.

Одним из основных направлений работы ГрозНИИ в области усовершенствования отечественного процесса алкилирования в 1960-е годы была разработка новых установок сернокислотного алкилирования.

ГрозНИИ и ВНИПИнефтью в 1968-1969 гг. был разработан и выдан регламент на проектирование новой установки производительностью 180 тыс. тонн/год по сырью, установки под шифром 25-8c [11, 8].

В качестве источника олефинового сырья было предусмотрено применение бутан-бутиленовой фракции. Регламент был утвержден Министерством НП и НХ промышленности СССР 21/Х-1969 года и на его основе ВНИПИнефтью был выполнен технический проект.

Согласно приказу Министерства №263 от 14 ноября 1968 г. проектирование универсальной установки 25-8c должно было быть закончено в 1970 году, а ее строительство на НХК г. Ангарска в 1972 году. Однако затем из-за изменения сырьевых плановых заданий сроки проектирования и строительства универсальной установки 25-8c были перенесены на более поздний период, а в существующий регламент ГрозНИИ были внесены значительные изменения.

При строительстве новых установок сернокислотного алкилирования изобутана олефинами ГрозНИИ была показана целесообразность использования новых эффективных конструкций контакторов, разработкой конструкции которых ГрозНИИ занималось особенно интенсивно в 1960-1970-е годы.

На этот период наиболее известными и эффективными конструкциями контакторов, исходя из анализа литературных источников, были многосекционный горизонтальный каскадного типа с внутренней циркуляцией для перемешивания, без охлаждающих элементов, с внутренним охлаждением за счет испарения изобутана, содержащегося в реакционной смеси, и односекционный горизонтальный с внутренним циркуляционным устройством и охлаждающими змеевиками виде U-образного пучка труб, с охлаждением при помощи потока из контактора [6]. 
Обе эти конструкции за счет внутренней циркуляции обеспечивали высокую концентрацию изобутана.

В результате проведенной совместно с заводами работы основные показатели установок в целом по отрасли несколько улучшились. Так, с 1968 по 1974 гг. по отрасли за счет улучшения показателей действующих установок выработка алкилата возросла на 120 тыс. тонн/год, его октановое число повысилось на 2,4 пункта (от 88,0 до 90,4), средний удельный расход серной кислоты понизился на 55 кг на тонну алкилата (с 241 до 186 кг). Себестоимость тонны алкилбензина понизилась на 16 руб. (с 118 до 102 руб. за тонну).

Вместе с тем достигнутые показатели значительно уступали зарубежным, особенно по расходу серной кислоты (186 кг на тонну алкилата против 70-100 кг за рубежом).

Кроме широкого круга исследований, реконструкций, проектирования и разработки новых установок по процессу сернокислотного алкилирования, ГрозНИИ одновременно проводилась работа по обмену передовым опытом эксплуатации алкилирующих установок в отрасли и мерам по улучшению их показателей.

В 1968 году сразу после назначения головным институтом в области процесса алкилирования ГрозНИИ было проведено всесоюзное совещание на тему: «Пути развития процесса сернокислотного алкилирования и интенсификации работы действующих установок», на котором специалисты ГрозНИИ совместно с представителями проектных организаций и заводов наметили основные пути дальнейшего развития процесса сернокислотного алкилирования.

По результатам анализа работы установок и итогам совещания Министерством при участии ГрозНИИ был подготовлен и издан 14/XI68г. приказ №263 по дальнейшему развитию процесса сернокислотного алкилирования и улучшению показателей работы действующих установок. Основные задания этого приказа в дальнейшем были выполнены.

Для материального стимулирования предприятий отрасли к повышению качества автомобильных бензинов ГрозНИИ совместно с НГНПЗ разработали систему дифференцированных оптовых цен на бензин АИ-93 в зависимости от содержания в нем алкилата и направили ее на рассмотрение Планово-экономическому управлению Миннефтехимпрома ССCP.

Исследованиями процесса алкилирования в ГрозНИИ в 1960-е годы занимались известные в отрасли ученые и ведущие специалисты А.3. Дорогочинский, Лютер А.В., Вольпова Е.Г., Шальковский Н.Г., Башилов А., Рехвиашвили А. и др.

\section{ЛИТЕРАТУРА}

1. Ахмадова Х.Х., Магомадова М.Х., Садаева Л.Ш. Алкилирующие установки бывшего CCCP // IV Международной научно-практической конференции «Достижения, проблемы и перспективы развития нефтегазовой отрасли», в рамках II Международного форума «Наука и Инновации». 2019. Альметьевск.

2. Вольпова Е.Г., Шальковский Н.Г. Обобщение опыта работы промышленных установок сернокислотного алкилирования изобутана бутиленами // Химия и технология топлив и масел. 1966. №8. С. 6-11.

3. Сернокислотное алкилирование изобутана бутиленами при различных способах питания контакторов / Вольпова Е.Г., Шальковский Н.Г., Жуков И.С., Пиихелаури В.А., Пинчевская С.И. // Химия и технология топлив и масел. 1962. №3. С.13-17.

4. Вольпова Е.Г., Шальковский Н.Г. Отчет ГрозНИИ по теме 65 за 1962 г. Решение технических вопросов, направленных на расширение химической промышленности ЧИАССР. 1962. С.65.

5. Вольпова Е.Г., Шальковский Н.Г. Отчет ГрозНИИ по теме 57 за 1960 г. Совершенствование процессов химической переработки газов. 1960. С.45.

6. Вольпова Е.Г., Шальковский Н.Г. Пути реконструкции промышленных установок сернокислотного алкилирования изобутана бутиленами // Нефтепереработка и нефтехимия. 1966. №5. С. 34-37 
7. Дорогочинский А.З. Доклад по процессу алкилирования 1970-1973 гг. 1973. С. 48.

8. Дорогочинский А.З. Доклад ГрозНИИ 1972-1973 гг.

9. Из опыта освоения установки сернокислотного алкилирования Ново-Ярославского НПЗ / Полякова А.И., Шальковский Н.Г., Павелко Э.М., Гараева Ф.Г., Оленев Л.М., Аренбристер B.B. // Нефтепереработка и нефтехимия. 1972. №3. С.7-9.

10. Из опыта освоения установки сернокислотного алкилирования Ново-Ярославского НПЗ / Полякова А.И., Шальковский Н.Г., Павелко Э.М., Гараева Ф.Г., Оленев Л.М., Аренбристер B.B. // Нефтепереработка и нефтехимия. 1973. №3. С.7-9.

11. Установка сернокислотного алкилирования изобутан олефинами типа 25-8c. / Хаджиев С.Н., Груздев А.С., Матаева Б.В., Авинезер А.М., Лютер А.В., Сапон М.Ф., Суманов В.Т., Шальковский Н. Г., Байбурский В.Л., Прохоренко В.И., Гордиенко Н.А. / Труды ГрозНИИ. Вып. XXX. Производство высокооктановых бензинов (Алкилирование и каталитический крекинг). 1976. С.14-20.

\title{
CONTRIBUTION OF THUNDERSTORM TO ALKYLATION PROCESS IN THE USSR IN 1960-E YEARS
}

\author{
(C) Kh.Kh. Akhmadova, M.H. Magomadova, Y.D. Tasueva \\ GSTOU named after acad. M.D. Millionshchikov, Grozny, Russia
}

\begin{abstract}
The purpose of work is establishment of a contribution of GROZNII to development of process of alkylation in the USSR in the 1960th years.

By authors it is established that all researches and reconstruction concerning process of sulphuric acid alkylation at domestic oil refineries in the 1960th years and up to the 1990th years were conducted with participation and under the direction of GROZNII.

For improvement of technology of process of alkylation and exchange of experience of GROZNII carried out collecting and synthesis of the basic data characterizing work of installations of the Orsk, Kuibyshev, Novokuibyshev, New and Ufa, New and Baku, Krasnovodsk and New Grozny Refinery for the period the 1960th years.

As a result of inspections and generalization of operating experience the alkiliruyushchikh of installations of GROZNII together with a number of the plants recommendations about improvement of indicators of their work, in particular on optimization of temperature condition in the reactor, on increase in concentration of the circulating isobutane in a system, on change of the scheme of supply of isobutane with parallel on consecutive for improvement of conditions of implementation of reaction of alkylation, on preparation of raw materials and increase in resources of the raw park, on replacement of steam turbines by electric motors, etc. were made and partially introduced.

In 1968 head functions on process of production of alkylgasoline in the USSR were charged to GROZNII as to research institute, made the significant contribution to development and formation of domestic process of alkylation.
\end{abstract}

Keywords: sulphuric acid alkylation, GROZNII, alkylgasoline, outputs, installations, contactors, reconstruction, raw materials. 


\section{REFERENCES}

1. Ahmadova, H.H., Magomadova, M.H. and Sadayev, L.S. (2019) 'Alkiliruyushchie ustanovki byvshego SSSR' IV Mezhdunarodnoi nauchno-prakticheskoi konferentsii «Dostizheniya, problemy i perspektivy razvitiya neftegazovoi otrasli», v ramkakh II Mezhdunarodnogo foruma «Nauka i Innovatsii». [Alkylating installations of the former USSR//IV International Scientific and Practical Conference "Achievements, Problems and Prospects of Development of Oil and Gas Industry," within the framework of the II International Forum "Science and Innovation"]. Almetyevsk.

2. Volpova, E. G. and Shalkovsky, N. G. (1966) 'Obobshchenie opyta raboty promyshlennykh ustanovok sernokislotnogo alkilirovaniya izobutana butilenami'. Khimiya i tekhnologiya topliv $i$ masel. [Synthesis of Experience of Industrial Installations of Sulfuric Acid Alkylation of Isobutane by Butylene. Chemistry and Technology of Fuels and Oils]. № 8. Pp. 6-11.

3. Volpova E. G., Shalkovsky N. G., Zhukov I. S. and Pizhelauri V.A., Pinchevskaya S. I. (1962) 'Sernokislotnoe alkilirovanie izobutana butilenami pri razlichnykh sposobakh pitaniya kontaktorov'. Khimiya i tekhnologiya topliv i masel. [Sernoacid alkylation of isobutane with butylene in various ways of feeding contactors. Chemistry and technology of fuels and oils]. №3. Pp. 13-17.

4. Volpova, E. G. and Shalkovsky, N. G. (1962) Otchet GrozNII po teme 65 za 1962g. Reshenie tekhnicheskikh voprosov, napravlennykh na rasshirenie khimicheskoi promyshlennosti ChIASSR. [Report of GrozNII on the topic of 65 for the year 1960. Solving technical issues aimed at expanding the chemical industry of CHIASSR]. p. 65.

5. Volpova, E. G. and Shalkovsky, N. G. (1960) Otchet GrozNII po teme 57 za 1960g. Sovershenstvovanie protsessov khimicheskoi pererabotki gazov. [Report of GrozNII on the topic of 57 for 1960. Improvement of processes of chemical processing of gases]. p. 45.

6. Volpova, E. G. and Shalkovsky, N. G. (1966) 'Puti rekonstruktsii promyshlennykh ustanovok sernokislotnogo alkilirovaniya izobutana butilenami'. Neftepererabotka neftekhimiya. [Ways of Reconstruction of Industrial Facilities for Sulfuric Acid Alkylation of Isobutane by Butylene. Petrochemicals Refining]. №5. Pp. 34-37

7. Dorogochinsky, A. Z. (1973) Doklad po protsessu alkilirovaniya 1970-1973gg. [The report on process of alkylation of 1970-1973]. p. 48.

8. Dorogochinskii, A.Z. Doklad GrozNII 1972-1973 gg. [Report of GrozNII 1972-1973].

9. Polyakov, A. I., Shalkovsky, N. G., Pavelko, E. M., Garayeva, F. G., Olenev, L. M. and Arenbrister, V. V. (1972) 'Iz opyta osvoeniya ustanovki sernokislotnogo alkilirovaniya NovoYaroslavskogo NPZ' Neftepererabotka i neftekhimiya. [From the experience of developing the plant of sulfuric acid alkylation Novo-Jarovsky refinery//Oil refining and petrochemicals]. №3. Pp. 7-9

10. Polyakova, A. I., Shalkovsky, N. G., Pavelko, E. M., Garayeva, F. G., Olenev, L. M. and Arenbrister, V. V. (1973) 'Iz opyta osvoeniya ustanovki sernokislotnogo alkilirovaniya NovoYaroslavskogo NPZ'. Neftepererabotka i neftekhimiya. [From the experience of developing the plant of sulfuric acid alkylation Novo-Jarovsky refinery//Oil refining and petrochemicals]. Pp. 7-9.

11. Hadzhiev, S. N., Gruzdev, A. S., Matayeva, B. V., Avinezer, A. M., Luther, A. V., Sapon, M. F., Sumanov, V. T., Shalkovsky, N. G., Baybursky, V. L., Prokhorenko, V. I. and Gorinokenko. (1976) Ustanovka sernokislotnogo alkilirovaniya izobutan olefinami tipa 25-8s. Trudy GrozNII. Vyp. KhKhKh. Proizvodstvo vysokooktanovykh benzinov (Alkilirovanie i kataliticheskii kreking). [Dikenko type. Works of GrozNII. Issue. XXX. Production of high-octane gasoline (Alkylation and catalytic cracking)]. Pp. 14-20 